\title{
EXTENT, APPLICABILITY, AND LEARNER SATISFACTION ON THE UTILIZATION OF RESEARCH MATERIALS FOR POST-PANDEMIC CURRICULA
}

\author{
Guinto $\mathrm{VMR}^{1 *}$, Terre $\mathrm{EQ}^{2}$, Taroma $\mathrm{MF}^{3}$, Ballesteros $\mathrm{J}^{4}$ and Camara \\ $\mathrm{JS}^{5}$ \\ ${ }^{1}$ Faculty, Pangasinan State University - Bayambang Campus, Philippines \\ ${ }^{2}$ Faculty, Pangasinan State University - Asingan Campus, Philippines \\ ${ }^{3}$ School Head, Carael National High School - Dagupan City, Philippines \\ ${ }^{4}$ Faculty, Pangasinan State University - Lingayen Campus, Philippines \\ ${ }^{5}$ Campus Research Coordinator, PSU Lingayen Campus, Philippines
}

\begin{abstract}
Instructional materials assume a central role to successful teaching and learning at the time of a pandemic. This study excerpt focused on the extent, applicability, and student satisfaction on the use of instructional materials utilized by research teachers in senior high schools in the Philippines, along with other study variables. Quantitative study design using the survey technique was employed and had generated 1,250 valid responses from college students all over the country. Findings showed that the majority of the participants were female, who graduated from the academic track in public senior high schools, particularly from the General Academic Strand. Findings revealed the use of instructional materials by their previous senior high school teachers to teach them research, and they are generally 'Satisfied'. Further, they claimed that such instructional materials in research could be applicable for instruction during the pandemic but, ironically, they also recommend that more student-friendly materials suitable for distance learning still be written. Further, statistical analysis evinced that 'Strand Type' but not Gender Identity, School Type, and School Track, appeared to be a moderator variable that influences the level of their satisfaction on the use of IMs and the choice to recommend a more student-friendly instructional material. With these findings, the researchers proposed a curriculum for a possible pattern of non-face-to-face research teaching for beginners and recommended periodic evaluation of the same once implemented in the field.
\end{abstract}

Keywords: curriculum, instructional materials, $\mathrm{k}$ to 12 , research, senior high school, updates

\section{Introduction}

In the Global Survey Report by the International Association of Universities published last May 2020 on the impact of COVID-19 on Higher Education around the world, a different pedagogy was realized to be required for distance teaching and learning - a realization which challenged faculty to make a sudden and unprepared shift from face-to-face to distance teaching and learning. What made this even roughly challenging was the observation that institutions themselves all around the world did not have a management structure employed before the pandemic hit which could have been used to capacitate their teaching and non-teaching personnel during the pandemic. The absence of a plan resulted in 
what the report called 'learning by doing' approaches, i.e. attempting to imitate what would have been the face-to-face way of proceeding, yet using distance modality. Whether or not institutions should have 'pandemic crisis plans', the reality is still striking - if there ever was a plan, it did not work; if there was none, the world saw there was really none.

The crippling effect of community lockdowns is self-evident, and physical attendance in schools in any part of the world seems to be an 'alternative' to the already embraced distance learning. At this time, social distancing and stay-at-home policies, while we wait for vaccines to drive herd immunity, are inevitable to slow down the spread of the disease. How could this interruption to the usual mode of education impact future generations? Reverting to the old ways where trial and error on how the world works was the standard of learning is not practical. Much has already been done to advance human knowledge, and a pandemic - while never seen in any millennial's life- is persisting. Mishra et al. (2020) opined that it is time to "gravely rethink, revamp and redesign" the educational system to circumvent the restrictions arising from the current situation. Further, they took the position that no pedagogical approach can replace the peak position of formal education. However, they also reiterated that the aftermath of the COVID-19 crisis will make online education a pedagogical shift from traditional methods to the modern approach of teaching-learning through online platforms and distance learning modalities from formal school and university education to seminars.

As early as 1971, Dr. Ivan Illich hypothesized that society can be de-schooled. According to him, both education and society are schooled. However, his view is irresponsible because it considers learning on one's own as unreliable, and the community organization, when not paid by those in authority, is a form of aggression or subversion. While most of his arguments are hard to be understood by the millennials, it could be inferred that he wanted to sell the idea that in the future, one needs not attend school to be educated. Interestingly, in the academic year 2020-2021 - after 50 long years - this shift is becoming not a challenge but an appropriate direction for educational institutions.

Indeed, distance education has become a part of what is called the 'new normal.' But this emergent situation never discounted the need of teaching and learning as two complementary processes done in an environment other than the classroom. Such an environment needs a continuous flow of ideas to which instructional materials are, to the researchers, the only possible alternatives that are common to all students regardless of socio-economic status. Thus, the need to identify the instructional materials' content is crucial because these- and the way these are sequenced - will, in part, replace the teachers' duty.

Whether curricula (and by extension, instructional materials) should be standardized or not, Noll (2005) quoted Mortimer would contend that democracy is best served by a public school system that establishes uniform curricular objectives for all students. On the contrary, Holt as quoted by Noll (2005), would argue that an imposed curriculum damages the individual and usurps a basic human right to select one's own path of development. On an entirely different perspective, the researchers believe that curricular planning - and by extension, instructional material development - is not anymore philosophical in a sense that our working ideology on what works better and in which type of environment is necessary. What works now is "practical," that is, feasible at the moment and in the years to come. 
Tety (2016) also emphasized that instructional materials are key to student's performance. He also emphasized that third world countries, like Tanzania and the Philippines, often lagged in international rankings because they suffer shortage of essential and practical instructional materials. It is manifested in a study of Rahon et al. (2021), where the research self-efficacy of K-12 Filipino graduates are deemed high, but the lowest-ranked competencies involve the analysis of data such as applying proper statistical analysis and selecting the proper research design, among others. This is probably due to the fact that these are sometimes not emphasized in the discussions or research teachers also lack such competencies. Moreover, sufficient instructional materials may also aid in filling up with the competencies.

Lev Vygotsky, a Russian psychologist and the author of Socio-cultural Theory of Teaching, Learning and Development, who held a view that tools and signs, which are in a form of instructional materials, have the capacity to develop in students' higher level of thinking, which is important in problemsolving activities. This theory posits that human's minds develop as a result of constant interactions with the social material world.

According to Vygotsky, human mind develops through interaction with materials in the learning process where people learn from each other and use their experiences to successfully make sense of the materials they interact with. These experiences are crystallized in 'cultural tools', and the learners have to master such tools in order to develop specific knowledge and skills in solving specific problems and, in the process, become competent in specific profession. In the classroom, these tools are often referred to as instructional materials. The researchers firmly believe that instructional materials employed in the classroom is necessary in all subject areas, including research subjects in the K-12 Curriculum.

In this study, the use and applicability of instructional materials used in the teaching of senior high school research subjects in the Philippines, viz: Qualitative Research, Quantitative Research, and Inquiries, Investigations and Immersion Subjects were assessed by college students who finished the $\mathrm{K}$ to 12 curriculum. The goal was two-fold: to present the 'experience' of the participants on the use of instructional materials in research as baseline nationwide data for other researchers, and to propose, based on the findings of the study, a curriculum that is more student-friendly to enhance the acquisition of research concepts and skills through distance learning.

\section{Methods}

\section{Research Design and Sampling Technique}

This study employed descriptive-status type of research because it attempts to observe and measure the characteristics of the research participants without any form of intervention or manipulation to any prevailing conditions that affect them (descriptive) but with possibility that these characteristics may be different with other populations and with the fact that these characteristics are present to the population under the study and during the data-gathering period (status). The sampling technique employed is simple random sampling for convenience and for wider geographical reach especially at a time when researcher mobility is limited to follow health protocols spelled out in the IATF guidelines of the country. 


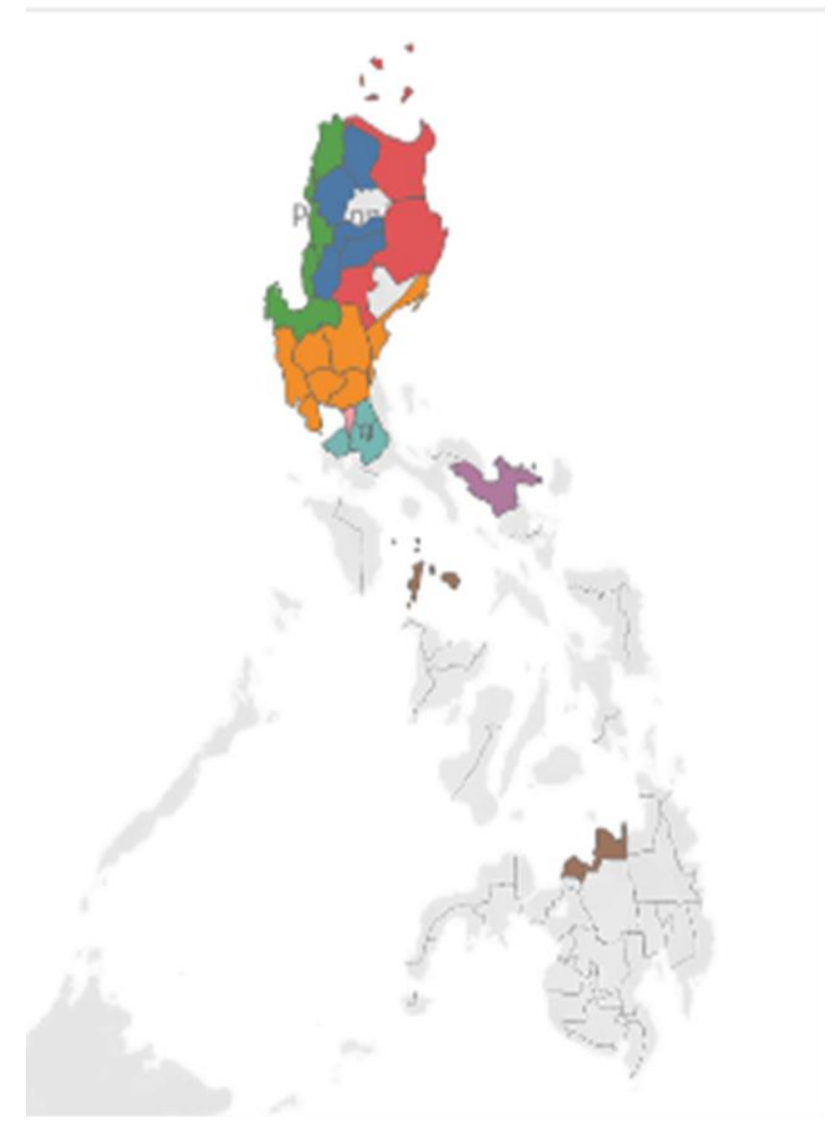

Figure 1: Provincial Distribution of the Participants ( $n=1250$ - Philippines)

\section{Population and Instrumentation}

The population of interest are (1) Filipino $\mathrm{K}$ to 12 graduates who are (2) enrolled in college during the data-gathering period. In this study, 1, 271 students participated but only 1, 250 of their responses were considered as data, because the remaining 21 responses were college students but were not graduates of $\mathrm{K}$ to 12 education. This study is delimited to the population of interest, college students who are graduates of the K-12 education, alongside with their demographic profile such as gender, type of school and strand. The study also focused on the experience on the use of instructional materials in research-based subjects in the K-12 Curriculum.

The research instrument is self-developed by the lead researcher. It is composed of 2 major parts. Part 1 included questions on the personal profile of the research participants including a few questions on their research profile as $\mathrm{K}$ to 12 graduates. Part 2 included self-efficacy questions relative to research writing. The research instrument underwent 2 major revisions and was finally rated as 'Very Highly Valid' $(\mathrm{M}=4.51)$ by experts of the Philippine Association of Research Practitioners, Educators and Statistical Software Users (PARESSU), Inc [SEC RN: CN2019001170]. The Ethics Board of the PARESSU, Inc rated it ‘Approved for Administration' dated October 10, 2020.

\section{Data-gathering Procedure and Data Analysis}

The data-gathering technique employed is the survey-questionnaire technique which was administered digitally all over the Philippines from October 15 to November 15, 2020 primarily through Messenger 
and Emails. Further, a social media invitation with the link of the google form was also posted on the website of PARESSU, Inc to ensure that every netizen who possessed the inclusion criteria is given an opportunity to participate in the study. For data analysis, the data for this excerpt - were subjected to simple frequency counts, percentage, and chi-square test of independence.

\section{Results and Discussion}

\section{Demographics}

Majority were female (783) respondents (62.6\%) and 437 were male respondents (35.0\%). A very few of the participants preferred not choosing between the options male or female and rather selected the option 'Prefer Not to Say'. Majority of the participants graduated from public senior high schools $(338,912,73.0 \%)$ while almost a third graduated from private senior high schools $(27.0 \%)$. Almost $98 \%$ of the sample graduated either from the Academic Track $(973,77.8 \%)$ or the Arts and Sports Track (257, 20.6\%). Most of the sample graduated from the General Academic Strand (366, 29.3\%). This is followed by graduates of Business, Accountancy and Management (259, 20.7\%), then by Strands under Arts and Sports $(228,18.2 \%)$, then by graduates of Technical-Vocational Livelihood Strand $(222,17.8 \%)$, and then from graduates of Humanities and Social Sciences (131, 10.5\%). There were a very handful of graduates from the Science, Technology, Engineering and Mathematics Strand who participated $(44,3.5 \%)$.

\section{Teachers' Use of Instructional Materials on Research}

Respondents were asked whether or not their senior high school teacher used an instructional material to teach them research. Majority of the sample answered "yes" $(1,018,81.4 \%)$, and a few answered "no" (90, 7.2\%). More than one-tenth of the sample could not recall whether their teacher used an instructional material to teach research or not. As evinced by the gathered data, this manifests that students have myriads of definitions when it comes to the use of instructional materials. The students have limited notion that instructional materials solely pertain to the books or modules which are provided by the department or by their respective schools. Teachers sometimes do not only cling on books since online resources are always available. However, the data revealed that the students do not consider these as instructional materials.

\section{Satisfaction of Participants on Instructional Materials}

They were asked their level of satisfaction of (any) instructional material which they used to learn research either as used by the teacher or as used by them as students in general. Majority of the sample are 'Satisfied' (617, 49.4\%), while many are even more 'Highly Satisfied' (384, 30.7\%). A few were 'Very Highly Satisfied'. Still, some were only 'Somewhat Satisfied' (106, 8.5\%) while a very few were 'Not Satisfied' at all $(26,2 . \%)$. It can be gleaned on the presented data that any instructional materials which are available, either provided by the teachers or the ones available online, satiate the craving of the respondents to learn bits of information pertaining to research. It also proves that the materials provided to them help them to learn and guide them to complete their researches required by their program. 


\section{Applicability of Instructional Materials During Pandemic}

They were asked whether or not the instructional materials which they used in senior high school were applicable for use as instructional material during pandemic. Majority of the sample answered 'Yes' $(654,52.3 \%)$, while a few answered 'No' $(150,12.0 \%)$. A number of the sample reasoned that they 'Could not decide' whether it could be applicable or not (446, 35.7\%). It is then safe to conclude that the instructional materials given to the respondents really help them to monitor their own amount of time or develop self-paced learning which is needed in this time of pandemic. Also, the respondents were free to set aside time for different learning activities, respond to check-in questions, gather resources, and complete the tasks that were assigned to them.

\section{Recommendation to Develop Pandemic-friendly Instructional Materials}

They were asked whether or not they recommend that an instructional material which is pandemicfriendly be written. Majority of the sample answered 'Yes' $(741,59.3)$ while a few answered 'No' $(117,9.4 \%)$. Still, a number 'Could not decide' $(392,31.4 \%)$. The results of the study suggest that the teachers shall provide quintessential and preconfigured instructional materials which will suit the current situation of the educational system. Further, teachers must create adaptive materials which will respond to the emerging education challenges and will guide and help the students during and following the pandemic. Hence, the students will not be discouraged nor disheartened despite the struggles and difficulties they experience brought by the pandemic.

Table 1: X2 and p-values on IMs Perception and Selected Profile Variables

\begin{tabular}{lll} 
Profile Variables & Satisfied with IM & Recommending an IM \\
\hline Gender Identity & 10.065 nsd $(0.261)$ & 8.954 nsd $(0.062)$ \\
\hline School Type & 5.659 nsd $(0.226)$ & $2.692 \mathrm{nsd}(0.260)$ \\
\hline School Track & $16.034 \mathrm{nsd}(0.190)$ & $7.145 \mathrm{nsd}(0.308)$ \\
\hline Strand Type & $40.012 *(0.005)$ & $21.186^{*}(0.020)$
\end{tabular}

Table 1 shows the chi-square values and the corresponding p-values (inside parentheses) of IMs perception and selected profile variables. As shown, no significant relationship was observed in any variables correlated except for Strand Type. The perception of whether or not the participants are satisfied with the IM used is influenced by Strand Type. Further, the decision to recommend a pandemic-friendly IM for research is influenced by Strand Type, as well.

\section{Conclusions and Recommendations}

The concept of 'curriculum' is as dynamic as the changes that occur in society. In its narrow sense, curriculum is viewed merely as a listing of subjects to be taught in school. In a broader sense, it refers to the total learning experiences of individuals not only in schools but in society as well (Bilbao, 2008). Since curriculum may greatly affect the whole development of an individual, it should be 
based on both standards and research. Moreover, students' attributes, aspirations and personal goals should be considered.

The results of this study showed that K-12 graduates are satisfied with the Instructional Materials used by their teachers in research subjects, but majority of the graduates recommend the construction of a more student-friendly and a more distance learning-friendly instructional materials in research. The results also show that the level of satisfaction of students in the utilization of instructional materials in research is influenced by their strand types.

Traditionally, students' curriculum has been made by the local government through recommendations. There are several government institutions in the Philippines whose recommendations became the anchor of reforms in education from all its areas, i.e., kindergarten, elementary, junior high school, senior high school, college, and post-graduate. The result of this study provides valuable information on the utilization of research materials for post-pandemic curricula. Hence, the researchers highly recommend the construction of more suitable instructional materials in teaching research by strand type.

\section{Declaration of Interest Statement}

The authors declare no conflicts of interests.

\section{References}

Illich, I. (1971). Deschooling society. New York: Harper \& Row

Bilbao, P., Lucido, P., Iringan, T, \& Javier, B. (2008). Curriculum Development. Lorimar Publishing, Inc: Manila, Philippines

Mishra, L., Gupta, T. \& Shree, A. (2020). Online Teaching-Learning in Higher Education during Lockdown Period of COVID-19 Pandemic. International Journal of Educational Research Open.

Marinoni, G., Land, H., \& Jensen, T. (2020). The Impact of COVID-19 on Higher Education Around the World: IAU Global Survey Report

Noll, J. W. (2005). Thinking Sides: Clashing Views on Controversial Educational Issues. 13e.

McGraw-Hill/Dushkin: United States of America

Rahon, C. A. M., Guinto, V. M. R., Terre, E. Q., Resueno Jr, C. P., \& Camara, J. S. (2021). 'We can do it now!': K to 12's Influence on Self-Efficacy of Filipino Researchers.

Tety, J. L. (2016). Role of Instructional Materials in Academic Performance in Community Secondary Schools in Rombo District" (Doctoral dissertation, The Open University of Tanzania). Vygotsky, Vygotzky L. S. (1978). Mind in Society. Cambridge: Harvard University press. 